\title{
Effects of social health insurance on access and utilization of obstetric health services: results from HIV+ pregnant women in Kenya
}

Lawrence P. O. Were ${ }^{1,2^{*}}$ D, Edwin Were ${ }^{3}$, Richard Wamai ${ }^{4}$, Joseph Hogan ${ }^{2}$ and Omar Galarraga ${ }^{2}$

\begin{abstract}
Background: Reducing maternal morbidity and mortality remains a top global health agenda especially in high HIV/AIDS endemic locations where there is increased likelihood of mother to child transmission (MTCT) of HIV. Social health insurance (SHI) has emerged as a viable option to improve population access to health services, while improving outcomes for disenfranchised populations, particularly HIV+ women. However, the effect of SHI on healthcare access for HIV+ persons in limited resource settings is yet to undergo rigorous empirical evaluation. This study analyzes the effect of health insurance on obstetric healthcare access including institutional delivery and skilled birth attendants for HIV+ pregnant women in Kenya.
\end{abstract}

Methods: We analyzed cross-sectional data from HIV+ pregnant women (ages 15-49 years) who had a delivery (full term, preterm, miscarriage) between 2008 and 2013 with their insurance enrollment status available in the electronic medical records database of a HIV healthcare system in Kenya. We estimated linear and logistic regression models and implemented matching and inverse probability weighting (IPW) to improve balance on observable individual characteristics. Additionally, we estimated heterogeneous effects stratified by HIV disease severity (CD4 < 350 as "Severe HIV disease", and CD4 > 350 otherwise).

Findings: Health Insurance enrollment is associated with improved obstetric health services utilization among HIV+ pregnant women in Kenya. Specifically, HIV+ pregnant women covered by NHIF have greater access to institutional delivery (12.5-percentage points difference) and skilled birth attendants (19-percentage points difference) compared to uninsured. Notably, the effect of NHIF on obstetric health service use is much greater for those who are sicker $(C D 4<350)$ - 20 percentage points difference.

Conclusion: This study confirms conceptual and practical considerations around health insurance and healthcare access for HIV+ persons. Further, it helps to inform relevant policy development for health insurance and HIV financing and delivery in Kenya and in similar countries in sub-Saharan Africa in the universal health coverage (UHC) era.

Keywords: Healthcare utilization, HIV/AIDS, Health insurance, Institutional delivery, Skilled birth attendants, Universal health coverage

\footnotetext{
* Correspondence: werelpo@bu.edu

'Department of Health Sciences, Boston University's College of Health and

Rehabilitation Sciences: Sargent College, Boston, USA

${ }^{2}$ School of Public Health, Brown University, Providence, RI, USA

Full list of author information is available at the end of the article
}

(c) The Author(s). 2020 Open Access This article is distributed under the terms of the Creative Commons Attribution 4.0 International License (http://creativecommons.org/licenses/by/4.0/), which permits unrestricted use, distribution, and reproduction in any medium, provided you give appropriate credit to the original author(s) and the source, provide a link to the Creative Commons license, and indicate if changes were made. The Creative Commons Public Domain Dedication waiver (http://creativecommons.org/publicdomain/zero/1.0/) applies to the data made available in this article, unless otherwise stated. 


\section{Background}

Reducing maternal mortality, a top global agenda for the past five decades has been central to the Millennium Development Goals (MDGs) and the ensuing Sustainable Development Goals (SDGs) [1] [2, 3]. While global maternal deaths have been declining, the situation is compounded by conditions such as HIV/AIDS that increase the risk of maternal death [4] [5]. Moreover, if these women develop obstetric complications especially in low-resource settings with no safety-net, they face catastrophic expenditures that threaten and push their households into poverty [6]. This also increases the likelihood of mother to child transmission (MTCT) of HIV [7]. Therefore, public investment in maternal healthcare to improve health outcomes is critical and greatly needed [8].

One strategy being implemented to reach the global goals for women's health is universal health coverage (UHC). UHC calls for access of all people to comprehensive health services at affordable costs and without financial hardship through protection against catastrophic health expenditures [9]. Sub-Saharan Africa (SSA) especially needs UHC given its high burden of HIV/AIDS and maternal mortality, and weak healthcare systems [9-11]. Numerous studies have shown that many HIV+ women have reproductive desires and are having children [12-15]. The result has been an estimated 1.4 million women living with HIV getting pregnant [16] with these women more likely to experience negative health and economic outcomes and overall low quality of life [17]. There is thus the need for prevention of MTCT of HIV, through skilled care during delivery [18]. This need is further amplified by the fact that global health funders have focused largely on HIV treatment programs leading to relative neglect of other reproductive health priorities including maternal health [19] [20].

In line with the UHC agenda, social health insurance (SHI) - membership in a health insurance scheme among all in the population [21] - has emerged as a viable option to improve population access to health services, while improving outcomes for disenfranchised populations, particularly $\mathrm{HIV}+$ women [22]. In SSA, Kenya offers a good opportunity to study the congruence of SHI, reproductive health and HIV related health outcomes as Kenya has been flagged as having potential to lead Africa towards UHC [23] [24]. Notably, Kenya has the oldest SHI in SSA: the National Hospital Insurance Fund (NHIF) [25] [26] and the 4th largest global HIV epidemic that is feminized as prevalence among women is $6.3 \%$ compared to men at $5.5 \%$ [27] [28].

\section{The National Hospital Insurance Fund (NHIF)}

An Act of Parliament established the NHIF in 1966 [26]. The 1966 Act was driven by the government's initial commitment to providing "free" health services as part of its development strategy to alleviate poverty and improve the welfare of Kenyans [26]. NHIF was mandated to deduct a graduated premium from wages and salaries of formal sector employees and covered the contributor, spouse, and children under 18 irrespective of the type of ailment [25]. However, efforts to expand coverage to all were constrained by several factors including a worsening HIV/AIDS crisis, a strained healthcare budget, and declining economic growth that pushed labor into the informal sector and affected the number of formal employees paying into the fund [25]. In 1998, NHIF was transformed from a government department to an autonomous parastatal [29]. The reform legislation provided for the NHIF to expand population access to high quality and affordable healthcare, be self-financing, monitor its own collections, distribute benefits to providers, and to make loans from its reserves to hospitals for service improvement [29]. Since then, the NHIF has instituted reforms that include management of inpatient and outpatient schemes for government employees; introduction of a quality improvement system; launch of health subsidies for the poor; revision of monthly premiums and increase in provider reimbursement rates through capitation; and accreditation of public and private hospitals to expand the provider network [30] [31] [32]. Under NHIF legislation, enrollment is based on which segment of the economy one is employed in. All formal sector employees and civil servants (government employees including military personnel) are mandatory members and their employers are obligated to deduct their monthly premiums from a portion of their gross salary [31]. On the other hand, informal sector workers and the self-employed can join voluntarily paying a flat monthly premium [31]. While there are no co-payments or co-insurance, those not enrolled in NHIF depend on out-of-pocket OOP or tax subsidized care in government facilities where quality is questionable [32]. However, the historical or contemporary impact of NHIF on members' utilization and access to healthcare for highrisk populations has not previously undergone rigorous empirical evaluation.

This paper thus analyzes the impact of NHIF on access to obstetric healthcare services including institutional delivery and skilled birth attendants for $\mathrm{HIV}+$ pregnant women in Kenya.

\section{Methods}

\section{Hypothesis and study setting}

We hypothesize that NHIF improves access and utilization of institutional delivery services, and maternal health and hence influences the well-being of HIV+ pregnant women. The hypothesis is based on economic theory suggesting that people purchase health insurance 
not only to avoid risk of financial loss, but also as a mechanism for gaining access to healthcare that would otherwise be unaffordable [33] [34]. We use data from the Academic Model Providing Access to Healthcare (AMPATH). AMPATH is one of the largest and most comprehensive HIV/AIDS healthcare systems in SSA providing care to more than 150,000 HIV+ individuals in Western Kenya, tests approximately 80,000 pregnant women annually for HIV, and has robust electronic medical records [35] [36]. AMPATH has also been at the forefront of helping the Kenya Ministry of Health $(\mathrm{MOH})$ formulate and implement healthcare policy initiatives and changes [37].

\section{Study design and variables}

The main data for this analysis comes from crosssectional records of medical encounters for HIV+ individuals within the AMPATH system between 2008 and 2013. The data is stored in the AMPATH Medical Records System (AMRS) - an electronic database of clinical encounters spanning more than 500 healthcare facilities in Western Kenya with extensive socio-demographic, economic, and biological variables [35]. The study population includes $\mathrm{HIV}+$ pregnant women (ages 15-49 years) who get their HIV care at AMPATH clinics and have had a delivery (full term, preterm, miscarriage) with their NHIF enrollment status available in the dataset. The study analytic samples comprise of HIV+ pregnant women whose information on their outcomes between 2008 and 2013 is complete. The Institutional Delivery and Skilled Birth Attendant samples are generated by intersecting the observed outcomes and reported insurance status leading to a cross-sectional dataset of the most recent observed outcomes.

The independent variable is NHIF enrollment (Yes/ No). The outcome or dependent variables are institutional delivery (birth at a hospital: Yes/No) and skilled birth attendant (SBA) -help by a nurse, doctor, or trained midwife at delivery: (Yes/No) - this is the WHO definition of SBA [38].

The dataset also includes the following covariates: age; number of children, access to electricity and piped water, education, Cluster of Differentiation antigen 4 (CD4) count, travel time to clinic, and clinic site (urban or rural). As detailed below, this high dimensional vector of covariates allows for appropriate regression adjustment and use of the observed characteristics of enrollment in NHIF to estimate the effect of insurance enrollment on outcomes based on matching methods.

\section{Statistical analysis}

First, we conduct bivariate analysis to determine the nature and degree of the relationship between enrolling in NHIF and socio-economic and demographic variables.
Next, we estimate the association between NHIF and obstetric healthcare access using unadjusted and adjusted linear and logistic models. Despite the outcomes being binary $(0,1)$, we use both linear and logistic regression models given that unless the probabilities being modeled are extreme, then linear and logistic models fit equally well and the linear model in the econometric literature is favored for ease of interpretation [39] [40]. Additionally, if the probabilities are extreme i.e. closer to $0 / 1$, then the logistic regression can suffer from complete separation, quasi-complete separation, and rare events bias especially in small samples [41].

To improve comparability as selection into insurance is not random, we implemented matching methods based on the conditional probability of enrolling in insurance given a set of observed covariates as defined by Rosenbaum and Rubin [42]. The matching estimation takes advantage of the covariates available in the dataset including their higher order terms (squares, cubes, and quadratics) and reduces bias due to differences in observed covariates thus balancing the covariates in the insured and uninsured groups [42]. After using the logit model in estimating the propensity scores and achieving balance of the propensity score between the insured and uninsured we estimate and report the 'average treatment effect on the treated' (ATT) i.e., the average response to treatment (insurance) for those pregnant women that enrolled in or were enrolled in health insurance. Specifically, we use three matching methods (stratification, kernel, and radius) to estimate ATT based on the propensity score [43]. The Stratification method consists of dividing the range of variation of the propensity score into intervals such that within each interval, treated and control units have on average the same propensity score [43]. Stratification method however discards observations in blocks where either treated or control units are absent [43]. In Radius matching, each treated unit is matched only with the control units whose propensity score falls into a predefined neighborhood of the propensity score of the treated unit - for this paper the radius is 0.01 . While in Kernel Matching, those insured are matched with a weighted average of all uninsured with weights that are inversely proportional to the distance between the propensity scores of insured and uninsured [43]. Both Radius and Kernel matching help address the limitations of stratified matching.

Additionally, we implemented inverse probability weighting (IPW). IPW weights subjects by the inverse probability of treatment received thus creating a synthetic sample in which treatment assignment is independent of measured baseline covariates and allows one to obtain unbiased estimates of average treatment effects [44]. IPW was implemented given the potential for unequal probabilities of NHIF enrollment [45]. The results 
from the IPW estimates are our preferred results in line with the literature [44]. Given that, this study is an observational cross-sectional study with a single treatment variable, as discussed by Bender and Lange 2001, multiple test adjustments were not performed [46]. All statistical analyses were implemented in Stata 13 with the program "pscore.ado" used for matching estimation and all standard errors bootstrapped.

\section{Heterogeneous effects}

Further, there is also the potential that the average effects estimated from the different models are heterogeneous for those with and without NHIF, and thus differ from the estimated average effects. The potential for impact heterogeneity is addressed by further stratifying the analysis based on HIV disease severity. HIV disease severity is defined using CD4 counts with $\mathrm{CD} 4<350$ as "Severe HIV disease," and CD4 > 350 otherwise [47].

\section{Results}

Descriptive statistics and association between NHIF and access to care

The analytic samples comprise of 1247 women (7\% insured) in the institutional delivery sample; and 1235 women (6\% insured) in the SBA sample. Table 1 shows that the mean age at enrollment in the study sample is 29 years. The ages when first pregnant at AMPATH, and age when pregnancy is first identified at AMPATH, are 4 and 8 months respectively after enrollment. Worth noting too, is that the uninsured HIV+ women have considerable loss to follow-up during pregnancy compared to the NHIF enrollees.

Table 1 Demographic and Socio-Economic Characteristics of HIV+ Pregnant Women by Health Insurance Status within AMPATH Electronic Medical Records

\begin{tabular}{|c|c|c|c|c|c|c|}
\hline \multirow[t]{2}{*}{ Mean Values } & \multicolumn{2}{|c|}{ Study Sample } & \multicolumn{2}{|c|}{ Institutional Delivery Sample } & \multicolumn{2}{|c|}{ Skilled Birth Attendant Sample } \\
\hline & $\overline{\mathrm{NHIF}}$ & Uninsured & $\overline{\mathrm{NHIF}}$ & Uninsured & $\overline{\mathrm{NHIF}}$ & Uninsured \\
\hline Outcome at Baseline (\%) & & & $\begin{array}{l}86.52 \\
(34.35)\end{array}$ & $\begin{array}{l}68.77 \\
(46.37)\end{array}$ & $\begin{array}{l}94.12 \\
(23.70)\end{array}$ & $\begin{array}{l}73.09 \\
(44.37)\end{array}$ \\
\hline Current Age & $\begin{array}{l}31.26 \\
(0.08)\end{array}$ & $\begin{array}{l}31.83 \\
(0.02)\end{array}$ & $\begin{array}{l}30.75 \\
(0.53)\end{array}$ & $\begin{array}{l}30.97 \\
(0.16)\end{array}$ & $\begin{array}{l}31.97 \\
(0.55)\end{array}$ & $\begin{array}{l}31.00 \\
(0.16)\end{array}$ \\
\hline Age at Enrollment & $\begin{array}{l}29.51 \\
(5.61)\end{array}$ & $\begin{array}{l}29.03 \\
(5.86)\end{array}$ & $\begin{array}{l}26.91 \\
(4.47)\end{array}$ & $\begin{array}{l}27.42 \\
(5.02)\end{array}$ & $\begin{array}{l}27.41 \\
(4.24)\end{array}$ & $\begin{array}{l}27.43 \\
(5.04)\end{array}$ \\
\hline Age First Pregnant @ AMPATH & $\begin{array}{l}30.43 \\
(5.92)\end{array}$ & $\begin{array}{l}29.80 \\
(6.15)\end{array}$ & $\begin{array}{l}27.53 \\
(4.74)\end{array}$ & $\begin{array}{l}28.05 \\
(5.32)\end{array}$ & $\begin{array}{l}28.34 \\
(4.76)\end{array}$ & $\begin{array}{l}28.14 \\
(5.39)\end{array}$ \\
\hline \# of Children & $\begin{array}{l}2.25 \\
(1.64)\end{array}$ & $\begin{array}{l}3.01 \\
(1.86)\end{array}$ & $\begin{array}{l}2.09 \\
(1.43)\end{array}$ & $\begin{array}{l}2.74 \\
(1.68)\end{array}$ & $\begin{array}{l}2.18 \\
(1.46)\end{array}$ & $\begin{array}{l}2.85 \\
(1.73)\end{array}$ \\
\hline Piped Water (\%) & $\begin{array}{l}39.29 \\
(47.35)\end{array}$ & $\begin{array}{l}12.84 \\
(35.89)\end{array}$ & $\begin{array}{l}35.96 \\
(48.26)\end{array}$ & $\begin{array}{l}12.68 \\
(33.31)\end{array}$ & $\begin{array}{l}25.00 \\
(43.62)\end{array}$ & $\begin{array}{l}10.70 \\
(30.94)\end{array}$ \\
\hline Electricity (\%) & $\begin{array}{l}36.91 \\
(46.88)\end{array}$ & $\begin{array}{l}10.54 \\
(33.72)\end{array}$ & $\begin{array}{l}38.20 \\
(48.86)\end{array}$ & $\begin{array}{l}11.23 \\
(31.58)\end{array}$ & $\begin{array}{l}30.90 \\
(46.54)\end{array}$ & $\begin{array}{l}10.10 \\
(30.16)\end{array}$ \\
\hline Ever Attended School (\%) & $\begin{array}{l}97.82 \\
(16.29)\end{array}$ & $\begin{array}{l}92.17 \\
(0.35)\end{array}$ & $\begin{array}{l}98.87 \\
(10.6)\end{array}$ & $\begin{array}{l}99.30 \\
(8.29)\end{array}$ & $\begin{array}{l}94.10 \\
(23.7)\end{array}$ & $\begin{array}{l}93.15 \\
(25.28)\end{array}$ \\
\hline Previous \# of Pregnancies & $\begin{array}{l}2.84 \\
(1.72)\end{array}$ & $\begin{array}{l}3.47 \\
(1.96)\end{array}$ & $\begin{array}{l}2.79 \\
(1.29)\end{array}$ & $\begin{array}{l}3.37 \\
(1.76)\end{array}$ & $\begin{array}{l}2.75 \\
(1.23)\end{array}$ & $\begin{array}{l}3.45 \\
(1.80)\end{array}$ \\
\hline CD4@ Enrollment & $\begin{array}{l}338.24 \\
(247.14)\end{array}$ & $\begin{array}{l}359.24 \\
(307.48)\end{array}$ & $\begin{array}{l}410.40 \\
(255.90)\end{array}$ & $\begin{array}{l}396.49 \\
(327.03)\end{array}$ & $\begin{array}{l}381.72 \\
(307.80)\end{array}$ & $\begin{array}{l}349.47 \\
(328.14)\end{array}$ \\
\hline Lost to Follow-up During Pregnancy (\%) & $\begin{array}{l}1.71 \\
(16.67)\end{array}$ & $\begin{array}{l}1.00 \\
(15.06)\end{array}$ & $\begin{array}{l}5.62 \\
(23.16)\end{array}$ & $\begin{array}{l}1.55 \\
(12.38)\end{array}$ & $\begin{array}{l}0.00 \\
(0)\end{array}$ & $\begin{array}{l}1.50 \\
(11.99)\end{array}$ \\
\hline Travel Time (Hours) & $\begin{array}{l}1.97 \\
(0.99)\end{array}$ & $\begin{array}{l}2.05 \\
(0.98)\end{array}$ & $\begin{array}{l}1.89 \\
(0.94)\end{array}$ & $\begin{array}{l}2.00 \\
(0.95)\end{array}$ & $\begin{array}{l}1.96 \\
(1.00)\end{array}$ & $\begin{array}{l}2.011 \\
(0.95)\end{array}$ \\
\hline Urban Clinic (\%) & $\begin{array}{l}70.06 \\
(47.59)\end{array}$ & $\begin{array}{l}44.80 \\
(50.0)\end{array}$ & $\begin{array}{l}69.70 \\
(46.23)\end{array}$ & $\begin{array}{l}42.06 \\
(49.39)\end{array}$ & $\begin{array}{l}69.12 \\
(46.54)\end{array}$ & $\begin{array}{l}37.53 \\
(48.44)\end{array}$ \\
\hline Observations N & $\begin{array}{l}1997 \\
(15.86 \%)\end{array}$ & $\begin{array}{l}10,596 \\
(84.14 \%)\end{array}$ & $\begin{array}{l}89 \\
(7.14 \%)\end{array}$ & $\begin{array}{l}1158 \\
(92.86 \%)\end{array}$ & $\begin{array}{l}68 \\
(5.51 \%)\end{array}$ & $\begin{array}{l}1167 \\
(94.49 \%)\end{array}$ \\
\hline Overall N & 12,593 & & 1247 & & 1235 & \\
\hline
\end{tabular}

Notes: The table shows the characteristics of HIV+ pregnant women in the AMPATH Medical Records System (AMRS) by their Health Insurance Status. The Study sample comprises of HIV+ pregnant women with information on their outcomes between 2008 and 2013 complete. The Institutional Delivery and Skilled Birth Attendant samples are generated by intersecting the observed outcomes and reported insurance status leading to a cross-sectional dataset of the most recent observed outcomes. In parentheses/brackets are the standard errors except for the "observations" row at the bottom of the table, which are percentages 
On the socio-economic front, HIV+ pregnant women enrolled in NHIF are more likely to have piped water and electricity at home, but no differences in education compared to the uninsured. Further NHIF enrollees seem to have shorter travel times and are more likely to receive their HIV care in urban settings.

The bivariate analysis results (Table 2) show that in both study samples, there exist significant differences in the mean values for the covariates among those enrolled in NHIF and those not enrolled. These differences are however not significant for the variables: age first pregnant at AMPATH, CD4 at enrollment and site of HIV clinic. As such, CD4 at enrollment is used in heterogeneous analysis.

Table 4 reports the linear and logistic regression models showing the association between NHIF and institutional delivery and access to SBA. The unadjusted linear and logistic models show that NHIF enrollees are 17 percentage points ( 3 times) more likely to deliver at an institution and 21 percentage points (6 times) more likely to have the services of a SBA at delivery. Both the adjusted linear and logistic models show attenuated but significant effects of having insurance on the two outcomes. This attenuation in effects might be indicative of confounding and the effect of selective enrollment into NHIF cannot be ruled out. Thus these potential limitations and biases are addressed through matching and IPW.

\section{Main results}

The main results are based on the propensity score estimation where Table 3 shows that there are not any statistically significant differences between the insured and uninsured in both matched analytic samples. The effect estimates from the matching methods are presented in Table 5 where results of different matching specifications including stratified, radius, and kernel matching are shown for the matched samples only. The average effect estimates from inverse probability weighting by logistic regression are also reported. Specifically, HIV+

Table 2 Bivariate Analysis of Association between Outcomes and Explanatory Variables of HIV+ Pregnant Women within AMPATH Electronic Medical Records

\begin{tabular}{|c|c|c|c|c|c|c|}
\hline \multirow[t]{2}{*}{ Mean Values } & \multicolumn{3}{|c|}{ Institutional Delivery Sample } & \multicolumn{3}{|c|}{ Skilled Birth Attendant Sample } \\
\hline & Yes & No & $P$ Values & Yes & No & P Values \\
\hline Current Age & $\begin{array}{l}30.80 \\
(0.18)\end{array}$ & $\begin{array}{l}31.35 \\
(0.30)\end{array}$ & 0.11 & $\begin{array}{l}30.90 \\
(0.18)\end{array}$ & $\begin{array}{l}31.49 \\
(0.32)\end{array}$ & 0.10 \\
\hline Age at Enrollment & $\begin{array}{l}27.19 \\
(0.16)\end{array}$ & $\begin{array}{l}27.87 \\
(0.27)\end{array}$ & $0.03^{* *}$ & $\begin{array}{l}27.24 \\
(0.16)\end{array}$ & $\begin{array}{l}27.96 \\
(0.30)\end{array}$ & $0.03^{* *}$ \\
\hline Age First Pregnant @ AMPATH & $\begin{array}{l}27.87 \\
(0.18)\end{array}$ & $\begin{array}{l}28.37 \\
(0.29)\end{array}$ & 0.12 & $\begin{array}{l}28.02 \\
(0.18)\end{array}$ & $\begin{array}{l}28.50 \\
(0.31)\end{array}$ & 0.17 \\
\hline \# of Children & $\begin{array}{l}2.56 \\
(0.05)\end{array}$ & $\begin{array}{l}3.03 \\
(0.09)\end{array}$ & $0.00^{* * *}$ & $\begin{array}{l}2.66 \\
(0.05)\end{array}$ & $\begin{array}{l}3.25 \\
(0.10)\end{array}$ & $0.00^{* * *}$ \\
\hline Piped Water (\%) & $\begin{array}{l}0.16 \\
(0.01)\end{array}$ & $\begin{array}{l}0.11 \\
(0.02)\end{array}$ & $0.02^{* *}$ & $\begin{array}{l}0.13 \\
(0.01)\end{array}$ & $\begin{array}{l}0.06 \\
(0.01)\end{array}$ & $0.00^{* * *}$ \\
\hline Electricity (\%) & $\begin{array}{l}0.16 \\
(0.01)\end{array}$ & $\begin{array}{l}0.06 \\
(0.01)\end{array}$ & $0.00^{* * *}$ & $\begin{array}{l}0.14 \\
(0.01)\end{array}$ & $\begin{array}{l}0.02 \\
(0.01)\end{array}$ & $0.00^{* * *}$ \\
\hline Ever Attended School (\%) & $\begin{array}{l}0.99 \\
(0.00)\end{array}$ & $\begin{array}{l}0.99 \\
(0.01)\end{array}$ & 0.34 & $\begin{array}{l}0.94 \\
(0.01)\end{array}$ & $\begin{array}{l}0.90 \\
(0.02)\end{array}$ & $0.01^{* *}$ \\
\hline Previous \# of Pregnancies & $\begin{array}{l}3.21 \\
(0.06)\end{array}$ & $\begin{array}{l}3.6 \\
(0.09)\end{array}$ & $0.00^{* * *}$ & $\begin{array}{l}3.28 \\
(0.06)\end{array}$ & $\begin{array}{l}3.77 \\
(0.11)\end{array}$ & $0.00^{* * *}$ \\
\hline CD4@ Enrollment & $\begin{array}{l}388.28 \\
(9.45)\end{array}$ & $\begin{array}{l}419.02 \\
(21.00)\end{array}$ & 0.12 & $\begin{array}{l}346.35 \\
(9.43)\end{array}$ & $\begin{array}{l}365.35 \\
(23.81)\end{array}$ & 0.37 \\
\hline Lost to Follow-up During Pregnancy (\%) & $\begin{array}{l}0.01 \\
(0.00)\end{array}$ & $\begin{array}{l}0.03 \\
(0.01)\end{array}$ & $0.06^{*}$ & $\begin{array}{l}0.01 \\
(0.00)\end{array}$ & $\begin{array}{l}0.03 \\
(0.01)\end{array}$ & $0.04^{* *}$ \\
\hline Travel Time (Hours) & $\begin{array}{l}1.96 \\
(0.03)\end{array}$ & $\begin{array}{l}2.08 \\
(0.05)\end{array}$ & $0.04^{* *}$ & $\begin{array}{l}1.97 \\
(0.03)\end{array}$ & $\begin{array}{l}2.11 \\
(0.05)\end{array}$ & $0.02^{* *}$ \\
\hline Urban Clinic (\%) & $\begin{array}{l}0.45 \\
(0.02)\end{array}$ & $\begin{array}{l}0.43 \\
(0.03)\end{array}$ & 0.60 & $\begin{array}{l}0.39 \\
(0.02)\end{array}$ & $\begin{array}{l}0.40 \\
(0.03)\end{array}$ & 0.88 \\
\hline Observations N & $\begin{array}{l}874 \\
(70.09 \%)\end{array}$ & $\begin{array}{l}373 \\
(29.91 \%)\end{array}$ & & $\begin{array}{l}917 \\
(74.25 \%)\end{array}$ & $\begin{array}{l}318 \\
(25.75 \%)\end{array}$ & \\
\hline Overall N & 1247 & & & 1235 & & \\
\hline
\end{tabular}

Notes: The table shows the results of bivariate analysis of the association between outcomes and explanatory variables of HIV+ Pregnant Women within AMPATH Medical Records System (AMRS). The $p$-values are based on a two-sample t-test with equal variance. In parentheses/brackets are standard errors except for the "observations" row at the bottom of the table, which are percentages. Significance levels: ${ }^{* * *} p<0.01,{ }^{* *} p<0.05,{ }^{*} p<0.1$ 
Table 3 Test of Balance of the Mean Propensity Score by Blocks

\begin{tabular}{llll}
\hline Panel A: Institutional Delivery Sample & & \\
\hline Block & Insured & Uninsured & P-Value \\
\hline Block 1 & 0.033 & 0.026 & 0.0395 \\
Block 2 & 0.066 & 0.062 & 0.1060 \\
Block 3 & 0.090 & 0.085 & 0.0305 \\
Block 4 & 0.153 & 0.139 & 0.0208 \\
Block 5 & 0.280 & 0.269 & 0.4175 \\
Block 6 & 0.457 & 0.480 & 0.6198 \\
N=1137 & 89 & 1048 & \\
Panel B: Skilled Birth Attendant Sample & & \\
Block & Insured & Uninsured & P-Value \\
Block 1 & 0.028 & 0.025 & 0.3297 \\
Block 2 & 0.073 & 0.070 & 0.4539 \\
Block 3 & 0.135 & 0.138 & 0.5857 \\
Block 4 & 0.256 & 0.250 & 0.7342 \\
Block 5 & 0.462 & 0.492 & 0.4877 \\
N=1017 & 68 & 949 & \\
\hline
\end{tabular}

Note: The above table reports the test of balance of the mean propensity score between the insured and uninsured by blocks. The results are from implementing "pscore.ado" program in Stata. The $p$-values are based on a twosample $t$-test with equal variance. The pscore command fits a logit (probit is the default) model with a starting specification of linear terms without interactions or higher order terms. If balance in not achieved in a block, the sample in the block is split into equally spaced intervals, with higher order terms and interactions included, and the average propensity score of the treated and controls is re-tested until balance is achieved

pregnant women with insurance are more likely to deliver at an institution. The effect estimates range from 10.2 percentage points for stratified matching to 15.5 percentage points for radius matching and 11.3 percentage points for kernel matching. The IPW estimate of 12.5 percentage points ( 2 times the odds) is almost an average of the three matching models. All the estimates are statistically significant at the 1 or 5 percent level.

For access to skilled birth attendants, the effect estimates of the impact of NHIF are 14.3 percentage points for stratified matching, 20.5 percentage points for radius matching, and 16.8 percentage points for kernel matching.
The IPW effect estimates $(\mathrm{OR}=5.17)$ are 1.6 percentage points higher than the average effect estimates from the matching models. All the estimates are statistically significant at the $1 \%$ level. For both outcomes, the matching based effect estimates are within the same range as the linear and logistic models presented in Table 4. This consistency in the magnitude of the effect estimates suggests robustness of the results to different specifications.

\section{Heterogeneous effects by HIV disease severity}

As discussed above, there is the potential for heterogeneity in the average effects estimated in this study. HIV disease severity is used to test for heterogeneity, with the results shown in Table 6.

The heterogeneous estimates show that those with severe HIV disease, across the different matching methods given their insurance status, utilize more care compared to those of higher CD4 count $(C D 4>350)$. For example, the IPW estimates show a 20 percentage-points difference $(\mathrm{OR}=4.09)$ for those enrolled in NHIF compared to those not insured with $\mathrm{CD} 4<350$. For access to SBA, there are similar differential access to care based on HIV disease state for those mothers with insurance compared to those not insured. These estimates are statistically significant at the $1 \%$ level.

\section{Discussion}

In this study looking at the influence of enrolling in the NHIF on utilization of obstetric services among HIV + pregnant women in western Kenya, we find that insurance is consistently associated with higher service utilization across different model specifications. Specifically, Table 1 shows that those with insurance are different from those $\mathrm{HIV}+$ pregnant women without insurance in terms of their sociodemographic characteristics - a difference that could be indicative of selective enrollment into NHIF. With SHI's goal being to ensure equitable access to care, these differences in demographics need to be addressed if more Kenyans are to benefit from NHIF. The fact that the

Table 4 Linear and Logistic Regression Estimates of the Effect of NHIF

\begin{tabular}{|c|c|c|c|c|c|c|c|c|}
\hline & \multicolumn{4}{|c|}{ Institutional Delivery } & \multicolumn{4}{|c|}{ Skilled Birth Attendant } \\
\hline & $\begin{array}{l}1 \text { Linear } \\
\text { Unadjusted }\end{array}$ & $\begin{array}{l}2 \text { Linear } \\
\text { Adjusted }\end{array}$ & $\begin{array}{l}3 \text { Logistic } \\
\text { Unadjusted [Odds } \\
\text { Ratio] }\end{array}$ & $\begin{array}{l}4 \text { Logistic Adjusted } \\
\text { [Odds Ratio] }\end{array}$ & $\begin{array}{l}5 \text { Linear } \\
\text { Unadjusted }\end{array}$ & $\begin{array}{l}6 \text { Linear } \\
\text { Adjusted }\end{array}$ & $\begin{array}{l}7 \text { Logistic } \\
\text { Unadjusted [Odds } \\
\text { Ratio] }\end{array}$ & $\begin{array}{l}8 \text { Logistic Adjustec } \\
\text { [Odds Ratio] }\end{array}$ \\
\hline NHIF & $\begin{array}{l}0.177^{* * *} \\
(0.039)\end{array}$ & $\begin{array}{l}0.118^{* * *} \\
(0.05)\end{array}$ & $2.91 * * *(0.921)$ & $2.34^{* * *}(0.832)$ & $\begin{array}{l}0.21^{* * *} \\
(0.03)\end{array}$ & $\begin{array}{l}0.161^{* * *} \\
(0.037)\end{array}$ & $5.89^{* * *}(3.06)$ & $5.08^{* * *}(2.80)$ \\
\hline $95 \% \mathrm{Cl}$ & $0.10-0.25$ & $0.04-0.20$ & $1.56-5.41$ & $1.16-4.70$ & $0.15-0.27$ & $0.09-0.23$ & $2.13-16.3$ & $1.73-14.97$ \\
\hline N & 1247 & 1247 & 1247 & 1247 & 1235 & 1235 & 1235 & 1233 \\
\hline Constant & $\begin{array}{l}0.688^{* * *} \\
(0.014)\end{array}$ & $\begin{array}{l}-1.06 \\
(4.163)\end{array}$ & $2.21(0.921)$ & $0.001(0.011)$ & $\begin{array}{l}0.731^{*} \\
(0.013)\end{array}$ & $\begin{array}{l}0.907 \\
(4.074)\end{array}$ & $2.72(0.179)$ & $0.51(11.17)$ \\
\hline $\begin{array}{l}\text { R } \\
\text { Squared }\end{array}$ & 0.01 & 0.08 & 0.009 & 0.07 & 0.012 & 0.084 & 0.014 & 0.083 \\
\hline
\end{tabular}


Table 5 Effect Estimates of the Impact of NHIF based on Matching Methods

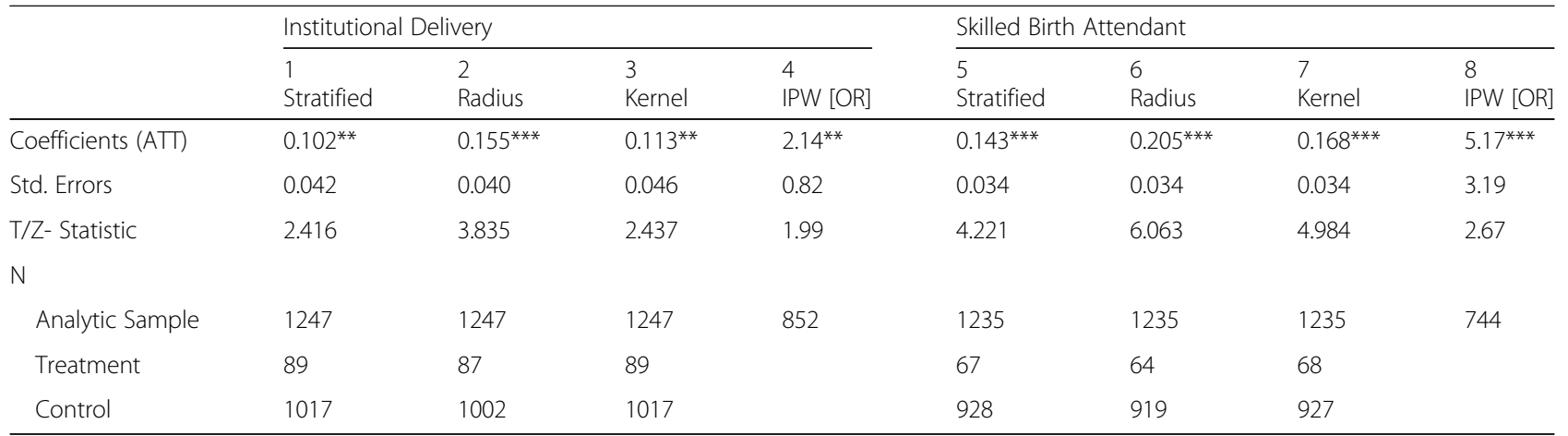

Notes: In the Table 4 above, models $1 \& 5$ are unadjusted linear models and $3 \& 7$ are unadjusted logistic models. Models $2 \& 6$ are linear models with controls and $4 \& 8$ are logistic with controls. The vector of controls include: age, household characteristics, education, pregnancy history, HIV care, travel time to clinics, and clinic sites (urban or rural). Reported for models $3,4,7 \& 8$ are Odds Ratios [OR]. In parentheses are robust standard errors. Significance levels: ${ }^{* * *} p<0.01$, ${ }^{* *} p<0.05,{ }^{*} p<0.1$. In Table 5, model $1 \& 5$ is Stratified matching; model $2 \& 6$ is Radius matching (radius $=0.01$ ); model 3 \& 7 is Kernel matching; and model 4 \& 8 is Inverse Probability Weighting (IPW) by logistic regression and results are Odds Ratios [OR]. The standard errors are bootstrapped. Significance levels: $* * *<$ $0.01,{ }^{* *} p<0.05,{ }^{*} p<0.1$. The results presented in the Table 5 above are for the matched samples only

Kenyan government's policies such as Vision 2030 are designed to help bridge this divide is encouraging.

Despite the differences identified in Table 1, the heterogeneous estimates in Tables 5 indicate that even with selection into NHIF, the sicker HIV+ mothers have greater access and utilization of institutional delivery and skilled birth attendants compared to those of higher
CD4 levels given their enrollment in NHIF. This may not be optimal for insurance design but a positive for healthcare policy. Moreover, it seems that those with lower CD4 are using more services because of higher need and the enabling effect of insurance. We may thus infer that NHIF seems to have positive effects on the sickest and disenfranchised HIV+ pregnant mothers.

Table 6 Heterogeneous Effect Estimates - HIV Disease Severity

\begin{tabular}{|c|c|c|c|c|c|c|c|c|}
\hline \multicolumn{9}{|c|}{ Panel A: Institutional Delivery } \\
\hline & \multicolumn{8}{|c|}{ HIV DISEASE } \\
\hline & \multicolumn{4}{|l|}{ CD4 $\leq 350$} & \multicolumn{4}{|l|}{ CD4 > 350} \\
\hline & $\begin{array}{l}1 \\
\text { Stratified }\end{array}$ & $\begin{array}{l}2 \\
\text { Radius }\end{array}$ & $\begin{array}{l}3 \\
\text { Kernel }\end{array}$ & $\begin{array}{l}4 \\
\text { IPW [OR] }\end{array}$ & $\begin{array}{l}5 \\
\text { Stratified }\end{array}$ & $\begin{array}{l}6 \\
\text { Radius }\end{array}$ & $\begin{array}{l}7 \\
\text { Kernel }\end{array}$ & $\begin{array}{l}8 \\
\text { IPW [OR }\end{array}$ \\
\hline Coefficients (ATT) & $0.124^{* *}$ & $0.18^{* * *}$ & $0.142^{* *}$ & $4.09^{* *}$ & 0.094 & 0.126 & 0.099 & $2.54^{*}$ \\
\hline T/Z- Statistic & 2.326 & 2.977 & 2.437 & 2.12 & 1.414 & 1.919 & 1.447 & 1.94 \\
\hline \multicolumn{9}{|l|}{ N } \\
\hline Analytic Sample & 640 & 640 & 640 & 640 & 607 & 607 & 607 & 607 \\
\hline Treatment & 40 & 40 & 40 & & 49 & 42 & 49 & \\
\hline Control & 523 & 505 & 523 & & 384 & 373 & 384 & \\
\hline & $\mathrm{CD} 4 \leq 350$ & & & & CD4 > 350 & & & \\
\hline Coefficients (ATT) & $0.116^{* * *}$ & $0.192^{* * *}$ & $0.154^{* * *}$ & $11.82^{* *}$ & $0.177^{* * *}$ & $0.215^{* * *}$ & $0.187^{* * *}$ & $8.12^{* *}$ \\
\hline Stand Errors & 0.043 & 0.052 & 0.046 & 9.24 & 0.056 & 0.057 & 0.062 & 7.00 \\
\hline T/Z- Statistic & 2.685 & 3.725 & 3.87 & 3.16 & 3.191 & 3.809 & 3.004 & 2.43 \\
\hline \multicolumn{9}{|l|}{$N$} \\
\hline Analytic Sample & 705 & 705 & 705 & 705 & 530 & 530 & 530 & 530 \\
\hline Treatment & 36 & 34 & 36 & & 31 & 29 & 32 & \\
\hline Control & 525 & 521 & 525 & & 376 & 365 & 375 & \\
\hline
\end{tabular}


Additionally, NHIF appears to work both at a practical and conceptual level and is therefore important for policy makers interested in UHC and SHI as a healthcare financing mechanism. However, it is hard to attribute this to any particular policy strategy in Kenya as NHIF is just undergoing reforms, and AMPATH in the period covered in this study had not instituted any social health insurance program or healthcare financing policy. Perhaps with the ongoing reforms, NHIF stands to provide greater benefits.

These findings are also consistent with the literature on multiple levels. First, given that eight months after enrollment, a positive pregnancy test result is identified, is an indicator that on average most mothers conceived and delivered after knowing their HIV+ status. This bolsters the literature that shows that women still have reproductive desires after knowing their HIV status [12$15]$.

Second, while this is the first study to look at the relationship between insurance and access to obstetric services for HIV+ pregnant women in a developing country context, and SSA in particular, it supports the findings from developed countries that show that insurance is generally associated with better health outcomes for HIV+ individuals [48] [49]. However, even the US studies did not focus on access to obstetric services for HIV+ pregnant women.

Third, the findings of the heterogeneous analysis fit within the frameworks that inform expansion of SHI. This supports the push by social scientists and policy makers for SHI as a viable option to improve access to $\mathrm{RH}$ services, while improving health outcomes for disenfranchised populations, particularly HIV+ women [17] [22]. Ultimately, any expansion of SHI to include HIV related care and treatment does raise the question of sustainability of health insurance. Beyond expanding the coverage pool to include as many as possible in the general population, sustainable SHI expansion would need to be buttressed by tax mechanisms such as general and progressive taxation [50].

However, these findings may be limited given the nature of and enrollment in NHIF, and the source of data. This is possible given non-random selection into NHIF and the fact that the AMPATH data is captured from clinical encounters and is not designed for evaluation of social programs. The study is also based on crosssectional observational data that are limited in causal estimation compared to experimental study designs. Nonetheless, given the extensive data and covariates available, the study tries to mimic experimental designs using matching methods in the estimation of the relationship between NHIF and obstetric healthcare access.

As SHI programs become more widely utilized in LMIC, SHI may be a valid and cost effective means to ensure access to RH services for HIV+ pregnant women. These findings should therefore be informative for countries with similar or comparable programs. Additionally, the HIV pandemic in Africa is highly feminized, and pediatric HIV is unacceptably high, thus our findings should be reflective of most SSA countries where HIV is highly generalized just as in Kenya. Finally, the AMPATH HIV treatment and prevention model is a well-developed system that may limit the comparability of our findings to other less developed systems and settings; however, the results may provide an upper-bound estimate in terms of the $\mathrm{RH}$ and insurance impact possibilities given a relatively well funded and well-managed HIV/AIDS care and PMTCT program.

\section{Conclusion}

Ultimately, this study shows that SHI improves utilization of obstetric services among HIV + pregnant women in Kenya. Other than answering the question on the impact of NHIF, this study is also policy relevant and timely. In Kenya, the ongoing reforms focus on NHIF as the primary vehicle for health care financing. Our findings show that despite reforms taking place with a limited evidence base, NHIF seems to be having an effect. This effect is taking place within the purview of NHIF's original mission and design - coverage of hospitalizations and institutional delivery. With declining funding for HIV/AIDS programs and the push by donors for increased country-level financing of HIV care, these findings show that it is possible to forge synergies essential for effective and sustainable HIV/AIDS policy, financing and programming. These findings thus help inform the UHC and HIV policy discussions both in Kenya and in similar countries around the global South.

\section{Abbreviations}

AIDS: Acquired Immune Deficiency Syndrome; AMPATH: Academic Model Providing Access to Healthcare; CD4: Cluster of Differentiation antigen 4; HIV: Human Immunodeficiency Virus; IPW: Inverse Probability Weighting; KDHS: Kenya Demographic and Health Survey; MDG: Millennium Development Goals; MMR: Maternal Mortality Rate; MOH: Ministry of Health; NGO: Non-Governmental Organizations; NHIF: National Health Insurance Fund; OOP: Out-of-Pocket; PMTCT: Prevention of Mother to Child

Transmission; SBA: Skilled Birth Attendants; SDG: Sustainable Development Goals; SHI: Social Health Insurance; SPA: Service Provision Assessment;

SSA: Sub-Saharan Africa; UHC: Universal Health Coverage; WHO: World Health Organization

\section{Acknowledgments}

We thank the Academic Model Providing Access to Healthcare (AMPATH) Kenya for providing the data used in this study.

\section{Authors' contribution}

LW contributed to the conception of the paper, data request, analysis and interpretation, drafting of the paper and subsequent revisions. EW contributed to the conception of the paper, drafts of the paper, interpretation of the data and revising of the paper. RW contributed to the conception of the paper, drafting of the paper, interpretation of the data and revision of the paper with a focus on the policy relevance and timeliness. JH contributed to the statistical methodology and approach, data 
analysis, interpretation of the data, and revision of the paper. OG contributed to the conception of the paper, statistical methodology and approach, data analysis, interpretation of the data, and revision of the paper. All authors read and approved the final manuscript.

\section{Funding}

This work is supported by: Hewlett Foundation/Institute of International Education (IIE), Lifespan/Tufts/Brown Center for AIDS Research (NIH/CFAR) (4P30AI042853-19) and Population Studies \& Training Center (PSTC) Brown University (2P2CHD041020-16). None of the funders were involved in the design of the study and collection, analysis, and interpretation of data and in writing the manuscript.

\section{Availability of data and materials}

The raw data analyzed for this study were obtained from AMPATH. The data is available from the corresponding author upon reasonable request, and after consultation and approval by the Institutional Research and Ethics Committee (IREC) at Moi University/Moi Teaching and Referral hospital in Eldoret, Kenya.

\section{Ethics approval and consent to participate}

All the data analyzed in this study was de-identified and from the AMPATH Medical Records System (AMRS). Thus, this study was not considered human subjects research. Nevertheless, the Institutional Research and Ethics Committee (IREC) at Moi University/Moi Teaching and Referral hospital in Eldoret, Kenya approved the study.

\section{Consent for publication}

Not applicable.

\section{Competing interests}

The authors declare no competing interests. The authors also acknowledge that Dr. Richard Wamai is a member of the editorial board of this journal i.e. he is an Associate Editor. However, Dr. Wamai was independent of the peer review and editorial process.

\section{Author details}

'Department of Health Sciences, Boston University's College of Health and Rehabilitation Sciences: Sargent College, Boston, USA. ${ }^{2}$ School of Public Health, Brown University, Providence, RI, USA. ${ }^{3}$ Department of Reproductive Health, Moi University \& AMPATH-Kenya, Eldoret, Kenya. ${ }^{4}$ Department of Cultures, Societies and Global Studies, Northeastern University, Boston, MA, USA.

Received: 28 January 2019 Accepted: 9 January 2020

Published online: 20 January 2020

\section{References}

1. WHO. The World Health Report 2005: Make every mother and child count. Geneva: World Health Organization; 2005.

2. Black RE, Laxminarayan $\mathrm{R}$, Temmerman M, Walker N. Reproductive, maternal, newborn, and child health: disease control priorities, third edition (volume 2). Washington (DC): The International Bank for Reconstruction and Development/The World Bank; 2016.

3. WHO, The Global Strategy for Women's, Children's and Adolescents' Health (2016-2030), World Health Organization, Geneva, 2015.

4. Gorman SE. A New Approach to Maternal Mortality: The Role of HIV in Pregnancy. Int J Women's Health. 2013;5, PMID: 23766661:271-4.

5. Kendall T, Danel I, Cooper D, Dilmitis S, Kaida A, Kourtis AP, Langer A, Lapidos-Salaiz I, Lathrop E, Moran AC, Sebitloane H, Turan JM, Watts DH, Wegner MN. Eliminating Preventable HIV-Related Maternal Mortality in SubSaharan Africa: What Do We Need to Know. J Acquir Immune Defic Syndr. 2014;67(Suppl 4, PMID: 25436825):S250-8.

6. Borghi J, Hanson K, Acquah CA, Ekanmian G, Filippi V, Ronsmans C, Brugha R, Browne E, Alihonou E. Cost of Near-Miss Obstetric Complications for Women and Their Families in Benin and Ghana. Health Policy Plan. 2003; 18(4, PMID: 14654514):383-90.

7. Taha TE. Mother-to-child transmission of HIV-1 in sub-Saharan Africa: Past, present and future challenges. Life Sci. 2011;88(21-22), PMID: 20933522): 917-21.
8. Desalegn H, Solberg E, Kim JY. The Global Financing Facility: Country Investments for Every Woman, Adolescent, and Child. Lancet. 2015;386:1056. https://doi.org/10.1016/S0140-6736(15)61224-7.

9. WHO. The World Health Report: Health Systems Financing: The Path to Universal Coverage. Geneva: World Health Organization; 2010.

10. GBD 2015 HIV Collaborators. Estimates of Global, Regional, and National Incidence, Prevalence, and Mortality between 1990 and 2015, with ScenarioBased Projections to 2030: A Systematic Analysis by the UN Maternal Mortality Estimation Inter-Agency Group. Lancet. 2016;387(10017), PMID: 26584737):462-74.

11. Rodin J, de Ferranti D. Universal Health Coverage: The Third Global Health Transition? Lancet. 2012;380(9845), PMID: 22959371):861-2.

12. Kaida A, Laher F, Strathdee SA, Janssen PA, Money D, Hogg RS, Gray G. Childbearing Intentions of HIV-Positive Women of Reproductive Age in Soweto, South Africa: The Influence of Expanding Access to HAART in an HIV Hyperendemic Setting. Am J Public Health. 2011;101(2), PMID: 20403884):350-8.

13. Kipp W, Heys J, Jhangri GS, Alibhai A, Rubaale T. Impact of antiretroviral therapy on fertility desires among HIV-infected persons in rural Uganda. Reprod Health. 2011;8:27. https://doi.org/10.1186/1742-4755-8-27.

14. Smee N, Shetty AK, Stranix-Chibanda L, Chirenje M, Chipato T, Maldonado Y, Portillo C. Factors Associated with Repeat Pregnancy AMong Women in an Area of High HIV Prevalence in Zimbabwe. Women's Health Issues. 2010; 21(3):222-9. https://doi.org/10.1016/j.whi.2010.11.005.

15. Tweya H, Feldacker C, Breeze E, Jahn A, Haddard LB, Ben-Smith A, Chaweza T, Phiri S. Incidence of Pregnancy Among Women Accessing Antiretroviral Therapy in Urban Malawi: A Retrospective Cohort Study. AIDS Behav. 2012; 17(2), PMID: 22354359):471-8.

16. UNICEF. For every child end AIDS: seventh stocktaking report, 2016. New York: United Nations Children's Fund; 2016.

17. Joshi S. Reproductive health and economic development: what connections should we focus on? Washington, DC: Population Reference Bureau; 2012.

18. NASCOP. Guidelines for prevention of mother to child transmission (PMTCT) of HIV/AIDS in Kenya. Nairobi: National AIDS \& STI Control Programme; 2012.

19. Schocken C. Overview of the Global Fund to Fight AIDS, Tuberculosis and Malaria. Washington DC: Center for Global Development; 2004.

20. Radelet S. The Global Fund to Fight AIDS, Tuberculosis and Malaria: Progress, potential, and Challanges of the future. Washington DC: Center for Global Development; 2004.

21. G. Carrin and C. James, Social Health Insurance: Key Factors Affecting the Transition toward Universal Coverage,International Social Security Review, vol. 58 (1), https://doi.org/10.1111/j.1468-246X.2005.00209.x, pp. 45-64, 2005.

22. Greene ME. Poor health, poor women: how reproductive health affects poverty. Washington, DC: Woodrow Wilson International Centerfor Scholars; 2008

23. Horton R. Offline: Africa does not need a Prince Charming. Lancet. 2017; 390(10102):1574. https://doi.org/10.1016/S0140-6736(17)32521-7.

24. Agyepong IA, Sewankambo N, Binagwaho A, Coll-Seck AM, Corrah T, Exeh A, Fekadu A, Kilonzo N, Lamptey P, Masiye F, Mayosi B, Mboup S, Muyembe J-J, Pate M, Sidibe M, Simons B, Tlou S, Gheorge A, Legido-Quigley H, McManus J, Ng E, O'Leary M, Enoch J, Kassebaum N, Piot P. The path to longer and healthier lives for all Africans by 2030: the Lancet Commission on the future of health in sub-Saharan Africa. Lancet. 2017;390(10114):280359. https://doi.org/10.1016/S0140-6736(17)31509-X.

25. Wamai RG. Recent international trends in NGO health system organization, development and collaborations with government in transforming health care systems: the case of Finland and Kenya. Helsinki: Institute of Development Studies; 2004.

26. Were LP, Were E, Wamai R, Hogan J, Galarraga O. The Association of Health Insurance with Institutional Delivery and Access to Skilled Birth Attendants: Evidence from the Kenya Demographic and Health Survey 2008-09. BMC Health Serv Res. 2017;17(1), PMID: 28673344):454

27. NACC. A case for smart investment in HIV and AIDS in Kenya. Nairobi: Ministry of Health; 2014.

28. NACC. Kenya AIDS response Progress report 2016. Nairobi: Ministry of Health; 2016.

29. Were LP The Informal Sector and Universal Health Coverage: Crucia Considerations. Issues in Brief No. 37. Boston University Pardee Center. Boston. June 2019; 1- 8. http://www.bu.edu/pardee/publications-library/ issues-in-brief/issues-in-brief-no-37-june-2019/. 
30. Deloitte. Strategic Review of the National Hospital Insurance Fund - Kenya. Nairobi: World Bank/FC; 2011.

31. NHIF. Strategic plan 2014-2018: sustainable financing toward universal health coverage in Kenya. Nairobi: National Hospital Insurance Fund; 2014

32. Barasa E, Rogo K, Mwaura N, Chuma J. Kenya National Hospital Insurance Fund Reforms: Implications and Lessons for Universal Health Coverage. Health Syst Reform. 2018;4(4):346-61.

33. Arrow KJ. Uncertainity and the Welfare Economics of Medical Care. Am Economic Review. 1963;53(5), PMID: 15042238):941-73.

34. Pauly MV. The economics of moral Hazard: comment. Am Econ Rev. 1968; 58(3):531-7.

35. Einterz RM, Kimaiyo S, Mengech HN, Khwa-Otsyula BO, Esamai F, Quigley F, Mamlin JJ. Responding to the HIV Pandemic: The Power of an Academic Medical Partnership. Academic Medicine. 2007;82(8), PMID: 17762264):812-8.

36. IUPUI, "AMPATH-Kenya," 16 September 2017. [Online]. Available: http://www. medicine.iupui.edu/kenya.

37. Mercer T, Gardner A, Andama B, Chesoli C, Christoffersen-Deb A, Dick J, Einterz R, Gray N, Kimaiyo S, Kamano J, Maritim B, Morehead K, Pastakia S, Ruhl L, Songok J, Laktabai J. Leveraging the power of partnerships: spreading the vision for population health care delivery model in Western Kenya. Glob Health. 2018;14:44. https://doi.org/10.1186/s12992-018-0366-5.

38. WHO. Making Pregnancy Safer: The Critical Role of Skilled Attendant: A Joint Statement by WHO, ICM and FIGO. Geneva: WHO; 2004.

39. Hellevik O. Linear Versus Logistic Regression when the Dependent Variable is a Dichotomy. Quality Quantity. 2009;43(1):59-74. https://doi.org/10.1007/ s11135-007-9077-3.

40. P. V. Hippel, Linear vs. Logistic Probability Models: Which is Better, and When?, 5 July 2015. [Online]. Available: https://statisticalhorizons.com/linearvs-logistic. [Accessed 5 August 2019].

41. King G, Zeng L. Logistic Regression in Rare Events Data. Political Analysis. 2001;9(2):137-63. https://doi.org/10.1093/oxfordjournals.pan.a004868.

42. Rosenbaum PR, Rubin DB. The Central Role of the Propensity Score in Observational Studies for Causal Effects. Biometrika. 1983;70(1):41-55. https://doi.org/10.1093/biomet/70.1.41.

43. Becker SO, Ichino A. Estimation of average treatment effects based on propensity scores. Stata J. 2002;2(4):358-77.

44. Austin PC, Stuart EA. Moving towards best practice when using inverse probability of treatment weighting (IPTW) using the propensity score to estimate causal treatment effects in observational studies. Statistics Medicine. 2015;34(28), PMID: 26238958):3661-79.

45. Mansournia MA, Altman DG. Inverse Probability Weighting. BMJ. 2016;352. https://doi.org/10.1136/bmj.i189.

46. Bender R, Lange S. Adjusting for Multiple Testing - When and How? J Clinical Epidemiology. 2001;54(4), PMID: 11297884):343-9.

47. WHO. What's New in Treatment Monitoring: Viral Load and CD4 Testing. Geneva: WHO Department of HIV/AIDS; 2017.

48. Goldman D, Leibowitz AA, Joyce G, Fleishman JA, Bozzette SA, Duan NN, Shapiro MF. Insurance Status of HIV-infected adults in the Post-HAART era: Evidence fron the United States. Appl Health Econ Health Policy. 2003;2(2), PMID: 14619279):85-90.

49. Goldstein RB, Rotheram-Borus J, Johnson MO, Weinhardt LS, Remein RH, Lightfoot M, Catz SL, Gore-Felton C, Kirshenbaum S, Morin SF, NIMH Healthy Living Trial Group. The Insurance Coverage, Usual Source of Care, and Receipt of Clinically Indicated Care for Comorbid Comditions Among Adults Living With Human Immunodeficiency Virus. Medical Care. 2005;43(4), PMID: 15778643):401-10

50. Liaropoulos L, Goranitis I. Health care financing and the sustainability of health systems. Int J Equity Health. 2015;14:80. https://doi.org/10.1186/ s12939-015-0208-5.

\section{Publisher's Note}

Springer Nature remains neutral with regard to jurisdictional claims in published maps and institutional affiliations.

Ready to submit your research? Choose BMC and benefit from:

- fast, convenient online submission

- thorough peer review by experienced researchers in your field

- rapid publication on acceptance

- support for research data, including large and complex data types

- gold Open Access which fosters wider collaboration and increased citations

- maximum visibility for your research: over $100 \mathrm{M}$ website views per year

At BMC, research is always in progress.

Learn more biomedcentral.com/submissions 